\title{
Determination of ultra-trace tellurium in steel by ID-ICP-MS/MS with liquid-liquid extraction
}

Junichi HIRATA, ${ }^{* \dagger}$ Daisuke ITABASHI, ${ }^{*}$ and Michihiro AIMOTO*

* Advanced Technology Research Laboratory, Nippon Steel Corporation, 20-1 Shintomi, Futtsu, Chiba 293-8511, Japan

${ }^{\dagger}$ To whom correspondence should be addressed.

E-mail: hirata.9za.junichi@jp.nipponsteel.com 


\begin{abstract}
Inductive ly coupled plasma mass spectrometry using is otope dilution (ID-ICP-MS) with liquid-liquid extraction was used for determining ultra-trace tellurium (Te) in steels to improve the sensitivity, accuracy, and precision of the analys is. Single quadrupole-type ICP-MS cannot be used to determine the trace amount of Te because of contribution of mass spectrometric interference by Xe. To overcome this, tandem mass-filter-type ICP-MS (ICP-MS/MS) was used for the determination of Te. Pretreatment by liquid-liquid extraction was also employed to compensate for the decrease in signal intensity due to the use of ICP-MS/MS. The relative standard deviations of the resulting abundances defined by repeated analys is from separated three steel samples were $<1.3 \%$. Furthermore, the determined values of Te in standard reference materials were close to the reference values. Thus, the developed determination method is useful for the analysis of ultra-trace Te in steels.
\end{abstract}

Keywords: Inductively coupled plasma mass spectrometry, Isotope dilution, Tellurium, Steel 


\section{Introduction}

In steel industry, controlling trace elemental composition in steels is important for both the manufacture of high-quality and stable products. Controlling the elemental components of steel is difficult because various raw materials are used for the iron-making and steel-making processes. Recently, traditional raw materials such as coal, iron ore, and limestone, as well as recycled materials such as plastics and gums have been used for iron making ${ }^{1,2}$. The use of recycled scrapped steel in the steel-making process has also increased ${ }^{3}$. The elemental composition of these recycled raw materials is often unknown, and thus, the impurity elements in products must be determined to control the quality of steel products ${ }^{4,5}$. Tellurium (Te) in steel is an impurity element that needs to be determined because trace $\mathrm{Te}$ in steel has an undesirable effect on the mechanical properties of products, such as ductility and brittle $^{6-8}$. For example, undesirable Te can produce inclusions or segregate in the steel, which can cause the crack of the steel. Flameless atomic adsorption spectrometry (FLAAS) is the most commonly used method for the determination of ultra-trace Te in steels ${ }^{9}$. The limit of quantification (LOQ) of Te by FLAAS proposed by Japan Industrial Standard (JIS) is $2 \mu \mathrm{g} \mathrm{g}^{-1}$, and, the precision of FLAAS becomes poor when the Te content is close to the LOQ. Inductively coupled plasma-mass spectrometry (ICP-MS) is another method to determine ultra-trace Te in steels. ICP-MS is expected to be a precise method for low trace amounts of Te in steels ${ }^{10,11}$. Despite this, there have been few reports on the determination of Te in steels by ICP-MS.

Various mass spectral interferences of $\mathrm{Te}$ have been extensively reported in previous reports ${ }^{12,13}$. Polyatomic ions containing molybdenum (Mo) and niobium $(\mathrm{Nb})$ can cause analytical error in the determination of Te in steels, because Mo and $\mathrm{Nb}$ are commonly contained as micro-alloys ${ }^{14}$. It is also known that Xe ions, which can be 
originating from air through engulfment, interfere with the mass spectrum of Te isotopes. The ICP-MS with a collision reaction cell (ICP-CRC-MS), high-resolution type ICP-MS (HR-ICP-MS), and ICP-tandem mass spectrometry (ICP-MS/MS) have been widely used to remove these mass spectral interferences. ICP-MS/MS has additional advantages, such as the ability to remove mass spectral interferences, ease of operation, or lower equipment costs compared with those of ICP-CRC-MS and HR-ICP-MS ${ }^{15}$. However, in the case of determining ultra-trace levels of Te in steels by ICP-MS/MS, the precision of the determined values becomes poor owing to deteroiation of the elemental sensitivity of Te. Thus, it is necessary to develop a precise method for the determination of ultra-trace Te in steels.

The purpose of this study was to establish a precise and accurate determination method for ultra-trace concentrations (few micrograms per gram) of Te in steels. First, the performance of ICP-MS/MS using calibration curve method was investigated in terms of reliability and precision. A recovery test of ultra-trace Te in the presence of Mo and $\mathrm{Nb}$ was also conducted to investigate the effect of their mass spectral interferences on Te isotopes. Second, for a more precise determination of ultra-trace Te, isotope dilution (ID)-ICP-MS/MS method was developed. To select the best conditions for ID-ICP-MS, the signal intensities of Xe ions were compared under various operational conditions. Xe ions were measured under conditions of single-mass mode without the CRC gas (no-gas mode), single mass mode using $\mathrm{He}$ gas (He collision mode), and tandem mass filtering mode using $\mathrm{O}_{2}$ gas $\left(\mathrm{O}_{2}\right.$ mass shift mode $)$. The mass discrimination effect on Te isotopes was also investigated for the accurate determination of Te by ID-ICP-MS/MS. Finally, liquid-liquid extraction using 4-methyl-2-pentanone was applied in the pretreatment of steels to reduce the contribution of the decrease in signal intensity due to the use of the $\mathrm{O}_{2}$ mass shift mode. The concentration of Te in the 
standard reference materials (SRMs) for steels was determined by ID-ICP-MS/MS, the applicability of the developed method was verified.

\section{Experimental}

\section{Reagents and samples}

Single elemental standard solutions (Kanto Che mical Corporation, Japan) of $\mathrm{Y}$ and $\mathrm{Te}$ were used for the calibration of Te. Single standard solutions (Kanto Chemical Corporation, Japan) of Mo and $\mathrm{Nb}$ were used to examine the effects of polyatomic ions. Prime pure-grade nitric acid $\left(\mathrm{HNO}_{3}\right)$ for sample decomposition and sulfuric acid $\left(\mathrm{H}_{2} \mathrm{SO}_{4}\right)$ for stocking Te in solutions were purchased from Kanto Che mical Corporation, Japan. The reagents used for liquid-liquid extraction were hydrochloric acid ( $\mathrm{HCl}$, prime pure-grade, Kanto Chemical Corporation, Japan), 4-methyl-2-pentanone (special-grade, Kanto Chemical Corporation, Japan), and potassium permanganate $\left(\mathrm{KMnO}_{4}, 0.2 \mathrm{~mol} / \mathrm{L}\right.$ for volumetric analys is, Kanto Che mical Corporation, Japan). The reagent for spiking ${ }^{125} \mathrm{Te}$ for isotope dilution was purchased from ISOFLEX Corporation. The abundance of various Te isotopes in the spike sample are shown in Table 1 which are provided by the ISOFLEX. This reagent is metallic Te, therefore, the sample was decomposed by acids according to the procedure described later in this section. Ultrapure water (18.2 $\mathrm{M} \Omega)$ was employed for all sample preparation. The concentration of the spike solution was determined by reverse isotope dilution method using ICP-MS/MS. The standard solution of Te containing natural isotopic abundance was used for the determination. The isotopic abundance of spike solution was measured using $\mathrm{O}_{2}$ mass shift mode as shown in Table 1 .

Electrolytic iron (purity $>99.999 \%$, MAIRON UHP, TOHO ZINC Corporation, Japan) was used for checking the blank, matrix matching of the standard solutions, and 
tests of Te recovery. SRM 361, SRM 363, and SRM 364 provided by the National Institute of Standards and Technology (NIST) were employed as the actual steel samples. The major elemental components of the SRMs are shown in Table 2.

\section{Instrumentation}

An Agilent 8800 (Agilent Technologies Corporation, Japan) was used for all measurements in this study. The operating conditions of Agilent 8800 are lis ted in Table 3. Other parameters, such as torch positions and mass axis, were automatically tuned using the mass spectra of $\mathrm{Li}, \mathrm{Y}$, and $\mathrm{Tl}$ prior to the Te determinations. The gas flow rate of $\mathrm{O}_{2}$ gas was set $30 \%$ because increasing of signal intensity of $\mathrm{TeO}^{+}$with increasing of $\mathrm{O}_{2}$ gas flow rate was saturated around this gas flow rate. It was difficult to select the best $\mathrm{He}$ collision gas flow rate, because the more $\mathrm{He}$ gas removed not only the polyatomic ions but also objective ions. Therefore, He gas flow rate was set to be the signal intensity of ${ }^{130} \mathrm{Te}^{+}$become more than $1000 \mathrm{cps}$ for $5 \mathrm{ppb}$ Te standard solution.

\section{Preparation of matrix-matched standards of Te}

Electrolytic iron was decomposed using $\mathrm{HNO}_{3}$ according to the procedure proposed by Hayashi et al. ${ }^{16}$. Electrolytic iron $(1 \mathrm{~g})$ and diluted $\mathrm{HNO}_{3}(30 \mathrm{~mL})$ were added to a quartz beaker and gently heated on a hot plate. After decomposition of the electrolytic iron, the sample solutions were transferred to $100 \mathrm{~mL}$ of volumetric vessels. Standard solutions of Te $\left(0,0.05,0.1\right.$, and $\left.0.5 \mu \mathrm{g} \mathrm{L}^{-1}\right)$ containing $100 \mathrm{mg} \mathrm{L}^{-1}$ of Fe were prepared for the determination of Te by calibration curve method. Te solutions $\left(0.1 \mu \mathrm{g} \mathrm{L}^{-1}\right)$ containing $1 \mathrm{mg} \mathrm{L}^{-1}$ of Mo or $\mathrm{Nb}$ and $100 \mathrm{mg} \mathrm{L}^{-1}$ of Fe were prepared to investigate the interference of $\mathrm{Fe}, \mathrm{Mo}$, and $\mathrm{Nb}$ spectra with $\mathrm{Te}$ mass spectra. The ratios of these elements were similar to those in steels containing $1 \%(\mathrm{w} / \mathrm{w})$ Mo or $\mathrm{Nb}$. 


\section{Liquid-liquid extraction for ID-ICP-MS/MS}

Figure 1 displays a schematic of Te determination by ID-ICP-MS in this study. The

${ }^{125}$ Te spiking reagent for is otope dilution was decomposed by $\mathrm{HNO}_{3}$, and the spike solution was diluted with $\mathrm{H}_{2} \mathrm{SO}_{4}$ according to the method proposed by $\mathrm{JIS}^{9}$. The spike solution was diluted to approximately $5 \mathrm{mg} \mathrm{kg}^{-1}$ of Te solution, and the spike of ${ }^{125} \mathrm{Te}$ was added to the quartz beakers before the decomposition of the steels. The steel samples were decomposed by $\mathrm{HNO}_{3}$ according to the procedure proposed by Hayashi et al. ${ }^{16}$ If any residue was observed in the decomposed sample, the residue was filtered away using a 5B filter paper (ADVANTEC Co.). Te in the residual fractions was negligible because Te in steel was contained as telluride metal such as FeTe and MnTe ${ }^{6,7}$, which were easily decomposed by nitric acids. It was expected that the residues were nitride, carbide, or oxide, which were difficult to decompose by $\mathrm{HNO}_{3}{ }^{17}$. To minimize adsorptions of $\mathrm{Te}$ on the surface of the residue, the residues were rinsed by diluted $\mathrm{HNO}_{3}$ after filtration. After diluting the sample solution in $100 \mathrm{~mL}$ volumetric flasks, 20 $\mathrm{mL}$ of the sample solutions were transferred to separatory funnels for liquid-liquid extraction.

The liquid-liquid extraction procedure was carried out according to the method proposed by $\mathrm{JIS}^{9}$. To oxidize $\mathrm{Te}^{4+}$ to $\mathrm{Te}^{6+}, \mathrm{KMnO}_{4}$ was added to each sample and left over 15 minutes until the color of the solution became purple. The sample solutions were mixed with $\mathrm{HCl}$ and 4-methyl-2-pentanone. The water phase was separated from the 4-methyl-2-pentanone phase after shaking the samples, where Fe and Mo were distributed in the 4-methyl-2-pentanone phase and Te was distributed in the water phase. The water phase was gently heated so that $\mathrm{Te}^{6+}$ could be reduced to $\mathrm{Te}^{4+}$ by $\mathrm{Cl}^{-}$ions. 4-methyl-2-pentanone and $\mathrm{HCl}$ were added to the separatory funnels again, and the water phase was removed after the extraction of $\mathrm{Te}^{4+}$ into the 4-methyl-2-pentanone 
phase. Ultra-pure water was added to the separatory funnels for the back extraction of $\mathrm{Te}^{4+}$ into the water phase. After the removal of the 4-methyl-2-pentanone phase, the water phase was gently heated on a hot plate to vaporize the remaining 4-methyl-2-pentanone in the water phase. The water phase containing $\mathrm{Te}^{4+}$ was added to $25 \mathrm{~mL}$ of volumetric flasks. The pretreated SRMs were measured by ICP-MS/MS. Recovery tests were also performed to validate the correctness of the analytical procedure using ID-ICP-MS and liquid-liquid extraction. In the case of the Te recovery test, $1 \mu \mathrm{g}$ of Te was added to the quartz beaker before the decomposition of electrolytic iron. The samples for the recovery tests were measured using no-gas mode, He collision mode, and $\mathrm{O}_{2}$ mass shift mode to compare the accuracy of the determined values of $\mathrm{Te}$ in each mode.

In the above oxidation step using $\mathrm{KMnO}_{4}$, all of the $\mathrm{Te}^{4+}$ must be oxidized to achieve isotope equilibrium. To check the oxidation rate, pre-experiment was performed. Reagent of $\mathrm{TeCl}_{4}$ was dissolved in ultra-pure water, and $\mathrm{KMnO}_{4}$ was added to the sample. Te in the resulting sample solution was extracted by 4-methyl-2-penthanon after adjusting of $\mathrm{HCl}$ concentration, and the concentration of $\mathrm{Te}$ in the water phase was determined by ICP-MS. Because more than $99 \%$ of Te was distributed in water phase, it is concluded that Te ion in solution was only $\mathrm{Te}^{6+}$.

\section{Determination of Te in steels by ID-ICP-MS/MS}

The obtained signal intensities were converted to Te concentrations using equation (1) ${ }^{18}$.

$$
C_{x}=C_{\text {spike }} \times \frac{m_{\text {spike }}}{m_{x}} \times \frac{A_{\text {spike }}-R_{\text {mix }} \times B_{\text {spike }}}{R_{\text {mix }} \times B_{x}-A_{x}}
$$

where $C_{x}$ is the molar concentration of Te in an objective sample, $C_{\text {spike }}$ is the molar 
concentration of $\mathrm{Te}$ in the spike solution, $\mathrm{m}_{\mathrm{x}}$ is the weight of the objective sample solution, and $\mathrm{m}_{\text {spike }}$ is the molar of the spike solution. $\mathrm{A}_{\text {spike }}$ and $\mathrm{B}_{\text {spike }}$ are the is otopic abundances of isotopes $A$ and $B$ in the spike solution, respectively. $A_{x}$ and $B_{x}$ are the is otopic abundances of isotopes $A$ and $B$ in an objective sample, and $R_{\text {mix }}$ is the isotopic ratio of isotopes $\mathrm{A}$ and $\mathrm{B}$ in the objective sample solution mixed with the $\mathrm{Te}$ spike solution. The measured signal intensities ( $\mathrm{I}_{\text {measur }}$ ) were corrected for the counting loss due to detector dead time based on qquation (2) ${ }^{18,19}$.

$$
I_{\text {true }}=\frac{I_{\text {mesur }}}{1-\tau \times I_{\text {mesur }}}
$$

Where, $\mathrm{I}_{\text {ture }}$ was the signal intensity after dead time correction, and $\tau$ was the dead time. The value of $\tau$ was $31.8 \mathrm{~ns}$ according to the previous study ${ }^{20}$, which was adjusted value by manufacturer. The concentration of Te in spike solution was recalibrated by the reverse isotope dilution (RID) method using following equation (3) ${ }^{21}$.

$$
C_{\text {spike }}=C_{\text {std }} \times \frac{m_{\text {std }}}{m_{\text {spike }}} \times \frac{R_{\text {std }}-R^{\prime} \text { mix }}{R^{\prime} \text { mix }-R_{\text {spike }}}
$$

$\mathrm{C}_{\text {spike }}$ and $\mathrm{C}_{\text {std }}$ are the molar concentration of Te in the spike and standard of Te, $\mathrm{m}_{\text {spike }}$ and $\mathrm{m}_{\text {std }}$ are the weights of the spike and standard solutions, $\mathrm{R}_{\text {spike }}$ and $\mathrm{R}_{\text {std }}$ are the measured isotope ratios of isotope A and B for the spike and the standard solutions, $\mathrm{R}_{\text {mix }}$ was the measured isotope ratios of isotope $\mathrm{A}$ and $\mathrm{B}$ for the solution mixing the spike and standard solution.

Isotopic abundance of Te is otopes in the spike solution was measured by the ICP-MS/MS (Table 1), and the values were substituted in equation (1) and (3). ${ }^{125} \mathrm{Te}$ and ${ }^{128} \mathrm{Te}$ were used for the determination using the ID and RID methods. The mixing ratio of the spike solution and the steel sample was adjusted based on ${ }^{125} \mathrm{Te}^{16} \mathrm{O}^{+}$. Based on 
previous study ${ }^{18}$, the signal intensity of ${ }^{125} \mathrm{Te}^{16} \mathrm{O}^{+}$from 50000 to 100000 cps was preferable for precise determination of $\mathrm{Te}$, when the concentration of $\mathrm{Te}$ was low. Therefore, mixing ratio was adjusted to follow the instruction, as well as possible. For the determination of spike solution, signal intensities of ${ }^{125} \mathrm{Te}^{16} \mathrm{O}^{+}$and ${ }^{128} \mathrm{Te}^{16} \mathrm{O}^{+}$were adjust to be about 200000 to $300000 \mathrm{cps}$, according to the instruction by Inagaki ${ }^{18}$. 


\section{Results and Discussion}

Evaluation of determination of Te by ICP-MS/MS using calibration curve method

The choice of Te isotopes for the isotope ratio measurement was key issue to avoid the erroreous measurements due to various mass spectral interferences, as shown in Table $4^{12,13,22}$. A recovery test of ultra-trace Te was conducted to examine the effect of the mass spectral interferences. Te solutions $\left(0.1 \mu \mathrm{g} \mathrm{L}^{-1}\right)$ were measured using the three modes, and each measurement was performed three times. The recoveries were calculated using Equation (4). If the recovery exceeds $100 \%$, it is considered that mass spectral interference affects the recovery because of an increase in signal intensity derived from other matrices.

$$
\text { Recovery }(\%)=\frac{\text { Determined weight of Te by measurement }(\mathrm{g})}{\text { Added weight of Te }(\mathrm{g})} \times 100
$$

As shown in Table 5 (a), the RSDs of the recoveries in the no-gas mode were 2.16.2\%. The RSDs obtained by $\mathrm{He}$ collision and $\mathrm{O}_{2}$ mass shift modes were exceeded this range because of a lowering signal intensities due to the collision-induced scattering effect. The Te in the Fe matrix was accurately determined by each condition. The $0.1 \mu \mathrm{g}$ $\mathrm{L}^{-1}$ of $\mathrm{Te}$ in the solution containing $100 \mathrm{mg} \mathrm{L}^{-1}$ of $\mathrm{Fe}$ and $1 \mathrm{mg} \mathrm{L}^{-1}$ of Mo or $\mathrm{Nb}$ was also determined by the calibration curve method three times to examine the effect of polyatomic ions from matrix elements in steels. As shown in Table 6 (b), the recoveries in the no-gas mode exceeded $100 \%$. In contrast, $100 \%$ of Te was recovered within the $2 \sigma$ under the other conditions. These results suggest that the polyatomic ions generated

from Mo can be removed by $\mathrm{He}$ collisions or $\mathrm{O}_{2}$ gas reactions. The recovery of ${ }^{125} \mathrm{Te}$ in the no-gas mode in Table 5 (b) exceeded $100 \%$ because of the contribution of Mo-related mass spectrometric interferences on $125 \mathrm{Da}$. It was assumed that the species 
of interference ions were ${ }^{92} \mathrm{Mo}^{16} \mathrm{O}_{2}{ }^{1} \mathrm{H}^{+}$and ${ }^{97} \mathrm{Mo}^{14} \mathrm{~N}_{2}{ }^{+}$. For $\mathrm{Nb}$ solutions, the recoveries at $m / z$ values of 125 and 126 exceeded $100 \%$, as shown in Table 5 (c). The mass spectral interference at $m / z$ values of 125 was ${ }^{93} \mathrm{Nb}^{16} \mathrm{O}_{2}{ }^{+}$, as reported in a previous study ${ }^{11}$, and the mass spectral interference at $m / z$ values of 126 was newly identified in this study. Although the interference at $m / z=126$ by $\mathrm{Nb}$ was not specifically identified, ${ }^{93} \mathrm{Nb}^{16} \mathrm{O}_{2}{ }^{1} \mathrm{H}^{+}$could be the interfering species. The interferences by $\mathrm{Nb}$ and Mo were removed in the $\mathrm{O}_{2}$ mass shift mode. In contrast, in the He collision mode, the interference by $\mathrm{MoO}_{2}{ }^{+}$was removed, whereas the interference by ${ }^{93} \mathrm{Nb}^{16} \mathrm{O}_{2}{ }^{+}$could not be removed (Table 5 (b)). The degree of mass spectral interference of ${ }^{93} \mathrm{Nb}^{16} \mathrm{O}_{2}{ }^{+}$onto ${ }^{125} \mathrm{Te}^{+}$was greater than that of $\mathrm{MoO}_{2}{ }^{+}$with ${ }^{125} \mathrm{Te}^{+}$. Thus, it was revealed that the $\mathrm{O}_{2}$ mass shift mode is a powerful protocol for the removal of the mass spectral interferences of Mo and $\mathrm{Nb}$. However, it was also revealed that precise determination of $\mathrm{Te}$ is difficult using the $\mathrm{O}_{2}$ mass shift mode. A precise method for the determination of ultra-trace Te in steels is still lacking. The data obtained here revealed that isolation of the Te through the chemical separation procedures, such as liquid-liquid extraction, are effective to improve both the precision and accuracy of the Te analysis.

\section{Examination of interference by Xe ions and mass discrimination effects of Te isotopes}

For the precise determination of ultra-trace Te in steels, determination by ID is the preferred technique. The accurate determination of Te by ID-ICP-MS is difficult because of the mass spectral interference by Xe ions and the mass discrimination effect among Te isotopes.

ID-ICP-MS requires two different interference-free isotopes; however, Xe ions contained in air interfere with the mass spectra of ${ }^{126} \mathrm{Te}^{+},{ }^{128} \mathrm{Te}^{+}$, and ${ }^{130} \mathrm{Te}^{+}$, which were relatively major Te isotopes. The background intensity was compared to examine the 
mass spectral interference caused by Xe ions. Fig. 2 shows the signals of Te isotopes obtaine d by each ICP-MS condition. The signals obtained in the no-gas and He collision modes were in good agreement with the natural is otopic abundance of Xe ions. The Xe ions were not removed selective ly by the $\mathrm{He}$ collision mode. Mono atomic ions $\left(\mathrm{Te}^{+}\right.$and $\mathrm{Xe}^{+}$) were less removed by $\mathrm{He}$ collision than polyatomic ions such as $\mathrm{MoO}_{2}^{+}$and $\mathrm{NbO}_{2}{ }^{+}$, because of the difference of collision probability. However, the abundance by the $\mathrm{O}_{2}$ mass shift mode was evidently different from the natural isotopic abundance of Xe.

The ions of $\mathrm{Te}^{+}$and $\mathrm{Xe}^{+}$could be separated by the difference in reactivity with $\mathrm{O}_{2}$ gas. The bimolecular reaction in the reaction cell is expressed as equation (5) and $(6)^{23,24}$.

$$
\begin{aligned}
& \mathrm{M}^{+}+\mathrm{O}_{2} \rightarrow \mathrm{MO}^{+}+\mathrm{O} \\
& \Delta_{\mathrm{r}} H=D_{0}\left(\mathrm{O}_{2}\right)-D_{0}\left(\mathrm{M}^{+}-\mathrm{O}\right)
\end{aligned}
$$

$D_{0}\left(\mathrm{O}_{2}\right)$ and $D_{0}\left(\mathrm{M}^{+}-\mathrm{O}\right)$ are the bond dissociation energy of $\mathrm{O}_{2}$ and $\mathrm{MO}^{+}, \Delta_{\mathrm{r}} H$ is the enthalpy of the bimolecular reaction. The reaction between an ion $\left(\mathrm{M}^{+}\right)$and $\mathrm{O}_{2}$ gas in the reaction cell proceed, when enthalpy $\left(\Delta_{\mathrm{r}} H\right)$ was bellow or nearby zero. The values of dissociation energy of $\mathrm{Xe}^{+}$and $\mathrm{Te}^{+}$were not reported as far as we know ${ }^{24,25}$. However, $\Delta_{\mathrm{r}} H$ of $\mathrm{Ar}^{+}$which is a noble gas as the same as $\mathrm{Xe}^{+}$, and $\Delta_{\mathrm{r}} H$ of $\mathrm{S}^{+}$and $\mathrm{Se}^{+}$which are the chalcogens as the same as $\mathrm{Te}^{+}$, were reported by the previous studies. It was reported that $\mathrm{Ar}+$ was not react with $\mathrm{O}_{2}$ gas because the $\Delta_{\mathrm{r}} H$ was positive value, and $\mathrm{S}^{+}$and $\mathrm{Se}^{+}$ were react with $\mathrm{O}_{2}$ gas because the $\Delta_{\mathrm{r}} H$ of $\mathrm{S}^{+}$was less than zero, and the $\Delta_{\mathrm{r}} \underline{H}$ of $\mathrm{Se}^{+}$was close to zero. Thus, $\mathrm{Xe}^{+}$could react with $\mathrm{O}_{2}$ gas not so much, and $\mathrm{Te}^{+}$react with $\mathrm{O}_{2}$ gas in the CRC. Mass spectral interference by Xe ions could be almost completely removed in the $\mathrm{O}_{2}$ mass shift mode due to the difference of the bond dissociation energy between $\mathrm{Xe}^{+}$and $\mathrm{Te}^{+}$.

It is generally know $\mathrm{n}$ that a mass discrimination effect causes bias in isotope ratio 
analys is $^{18,26,27}$. The standard solution of Te with natural isotopic abundance was analyzed by ICP-MS/MS to examine the effect of the mass discrimination. $25 \mu \mathrm{g} \mathrm{g}^{-1}$ of Te solution was measured because the signal intensity of ${ }^{128} \mathrm{Te}^{16} \mathrm{O}^{+}$was close to the signal intensity of the recovery test and steel samples. The measured RSDs by ICP-MS/MS were 2.66 to 4.82 (Table 6), suggesting that changes of the mass discrimination effect could not be detected by the present operating conditions and system set up used for this study. There is a possibility to detect the mass discrimination effect, when higher concentration of Te standard solution is measured. However, the use of high concentration of $\mathrm{Te}$ standard solutions for the correction of the mass discrimination effect by comparis on method can cause another problem. The memory of the sample introduction tube has to be washed out completely for the determination of ultra-trace tellurium, which is highly time-consuming. On the other hand, it is known that the correction factor is slightly varied during the analys is ${ }^{18}$. This point seemed the common and difficult problem in the field of the determination of ultra-trace elements by ID-ICP-MS/MS. The selection of the mass bias correction method ${ }^{28,29}$, such as comparison method, internal correction method, or external correction method was expected to be examined by further research.

The mass discrimination effect on Te isotopes were not considered for the determination of $\mathrm{Te}$ in this study, because the effects of mass discrimination were smaller than analytical uncertainties achieved in this study. Even though the measured value of ${ }^{130} \mathrm{Te} /{ }^{125} \mathrm{Te}$ was agree within $2 \sigma$ with the natural isotopic abundance, ${ }^{130} \mathrm{Te} /{ }^{125} \mathrm{Te}$ might be slightly higher than the natural isotopic abundance. ${ }^{128} \mathrm{Te} /{ }^{125} \mathrm{Te}$ was used for ID-ICP-MS in this study to minimize the effect of mass discrimination effect, because the natural isotopic abundance of ${ }^{128} \mathrm{Te}$ was the second largest. 
Determination of Te in steels by ID-ICP-MS/MS with liquid-liquid extraction

As shown in Tables 5, the RSDs by the $\mathrm{O}_{2}$ mass shift mode using calibration curve method were not sufficient for the precise determination of Te because of a decreased signal intensity. A pre-concentration of Te through the liquid-liquid extraction technique was applied in the present ID-ICP-MS/MS to improve both the signal-to-noise ratio and precision of the signals. The results of recovery tests by ID-ICP-MS after liquid-liquid extraction are shown in Table 7. The recoveries of Te obtained with no-gas mode and He collision mode exceeded $100 \%$ because of mass spectral interference by Xe ions. The recoveries of $\mathrm{Te}$ in the $\mathrm{O}_{2}$ mass shift mode were close to $100 \%$. Furthermore, the RSDs obtained by the analys is from separated three steel samples was $0.52 \%$, which is better than those obtained using the calibration curve method shown in Table 5 (a).

Finally, Te contents in the SRMs were determined by the developed method, as shown in Table 8 . Te values determined by ID-ICP-MS/MS with liquid-liquid extraction are close to the reported values provided by NIST. Furthermore, the RSDs of SRM 361, SRM 363, and SRM 364 were $0.78,0.51$, and 1.3\%, respectively. These results are remarkable, considering that the experiment was performed independently from sample preparation to measurement. Thus, it is confirmed that ID-ICP-MS/MS with pretreatment by liquid-liquid extraction can be used for the accurate and precise determination of ultra-trace Te in steels.

\section{Conclusion}

ID-ICP-MS/MS with liquid-liquid extraction is proposed to achieve a precise and accurate determination of ultra-trace Te in steels. This study revealed the following:

(1) The mass spectral interference by Xe ions was almost completely removed in the $\mathrm{O}_{2}$ mass shift mode by ICP-MS/MS, which was advantageous for the determination of Te 
by ID.

(2) The RSDs by ID-ICP-MS/MS after liquid-liquid extraction were $0.51-1.3 \%$, better than those obtained by ICP-MS with the calibration curve method.

(3) Te added to electrolytic iron was recovered by almost $100 \%$ by the developed method, and the determined values of Te in SRMs were close to the values reported by NIST.

Thus, the validity and superiority of the proposed method are confirmed. The developed method for ultra-trace Te determination in steels will facilitate the stable production of high-quality steel. 


\section{References}

1. J. R. Dankwah, P. Koshy, N. M. Saha-chaudhury, P. O’kane, C. Skidmore, D. Knights, and V. Sahajwalla, ISIJ Int., 2011, 51, 498.

2. H. Kuwatori, Tetsu-to-Hagane, 2014, 100, 59.

3. C. Ryman and M. Larsson, ISIJ Int., 2006, 46, 1752.

4. K. Fujimoto, M. Shimura, and S. Satoh, Tetsu-to-Hagane, 2002, 88, 285.

5. H. Naka and T. Nakahara, Tetsu-to-Hagane, 2014, 100, 857.

6. D. Bhattacharya and D. T. Quinto, Metall. Trans. A, 1980, 11A, 919.

7. T. Shiraga and Y. Shingaki, "Tekkouzairyou to goukingenso (Steels and alloying elements, in Japanese)", ed. M. Enomoto, 2015, Chap. 29, Iron and steel institute of Japan, Tokyo.

8. Z. Takao, Bunseki Kagaku, 1967, 16, 1104.

9. JIS G 1257-18-2, "Iron and steel-Atomic absorption spectrometric method-Part 18:

Determination of tellurium-Section 2: Electrothermal atomization”, 2013, Japanese Industrial Standards Committee, Tokyo.

10. K. Fujimoto, M. Shimura, and S. Satoh, ISIJ Int., 2002, 43, 101.

11. G. Okano, S. Igarashi, O. Ohno, Y. Yamamoto, S. Saito, and Y. Oka, ISIJ Int., 2015, 55,332 .

12. J. Hu and H. wang, Microchim. Acta, 2001, 137, 149.

13. T. W. May and R. H. Wiedmeyer, Atom. Spectrosc., 1998, 19, 150.

14. H. Mohrbacher, Metals, 2018, 8, 234.

15. L. Balcaen, E. B. Fernandez, M. Resano, and F. Vanhaecke, Anal. Chim. Acta, 2015, 894,7 .

16. K. Hayashi and T. Ogata, Bunseki Kagaku, 1966, 15, 1120. 
17. Y. Yoshida and I. Kanji, Bunseki Kagaku, 1979, $28,733$.

18. H. Tao, Y. Iida, K. Inagaki, J. Takahashi, and T. Nakazato, "Yudoketsugo plasma shitsuryo bunseki (Inductively coupled plasma mass spectrometry, in Japanese)", ed. H. Haraguchi, H. Ishida, H. Ohtani, T. Suzuki, H. Seki, and H. Watarai, Kyor its ushuppan, Tokyo, 160.

19. S. M. Nelms, C. R. Quétel, T. Prohaska, J. Vogl, and P. D. P. Taylor, J. Anal. At. Spectrom., 2001, 16, 333.

20. A. Gourgiotis, T. Ducasse, E. Barker, P. Jollivet, S. Gin, S. Bassot, C. Cazala, Anal. Chim. Acta, 2017, 954, 68.

21. N. Nonose, A. Hioki, M. Kurahashi, and M. Kubota, Bunseki Kagaku, 1998, 47, 239.

22. J. Meija, T. B. Coplen, M. Berglund, W. A. Brand, P. D. Bivère, M. Gröning, N. Holden, J. Irrgeher, R. D. Loss, T. Walczyk, and T. Prohaska, Pure Appl. Chem., 2016, $88,293$.

23. N. Yamada and J. Takahashi, Bunseki Kagaku, 2018, 67, 249.

24. G. K. Koyanagi, D. Caraiman, V. Blagoje vic, and D. K. Bohme, J. Phys. Chem. A., $\mathbf{2 0 0 2}, 106,4581$.

25. T. Narukawa and K. Chiba, Anal. Sci., 2013, 29, 747.

26. A. J. Walder and I. Platzner, J. Anal. At. Spectrom., 1993, 8, 19.

27. L. Yang, S. Tong, L. Zhou, Z. Hu, Z. Mester, and J. Meija, J. Anal. At. Spectrom., 2018, 33, 1849 .

28. T. Hirata, Bunseki Kagaku, 1996, 45, 465.

29. Y. Shimamura and I. Nakai, Bunseki Kagaku, 2013, 62, 774. 
Table 1 Isotopic abundances of spike solution

$(\%: \mathrm{w} / \mathrm{w})$

\begin{tabular}{cccccccccc}
\hline & & ${ }^{120} \mathrm{Te}$ & ${ }^{122} \mathrm{Te}$ & ${ }^{123} \mathrm{Te}$ & ${ }^{124} \mathrm{Te}$ & ${ }^{125} \mathrm{Te}$ & ${ }^{126} \mathrm{Te}$ & ${ }^{128} \mathrm{Te}$ & ${ }^{130} \mathrm{Te}$ \\
\hline \multirow{3}{*}{ Measured* } & No 1 & n. d. & n. d. & n. d. & 0.033 & 99.79 & 0.040 & 0.0011 & 0.13 \\
& No 2 & n. d. & n. d. & n. d. & 0.037 & 99.79 & 0.037 & 0.0012 & 0.13 \\
& No 3 & n. d. & n. d. & n. d. & 0.034 & 99.80 & 0.042 & 0.0006 & 0.12 \\
\cline { 2 - 10 } & Average & \multirow{2}{*}{ n. d. } & n. d. & n. d. & 0.035 & 99.80 & 0.040 & 0.0010 & 0.13 \\
& $\pm \sigma$ & & & & & & & & \\
ISOFLEX** & & 0.01 & 0.002 & \pm 0.01 & \pm 0.002 & \pm 0.0003 & \pm 0.01 \\
\hline
\end{tabular}

*The spike solution was measured three times by ICP-MS/MS using $\mathrm{O}_{2}$ mass shift mode. The isotopic abundances were calculated by [Signal intensity of a Te isotope] $\div$ [Sum of the signal intensity of all of the Te isotopes] $\times 100$. The error ranges for the average values were standard deviations.

**The values were provided by the ISOFLEX Corporation, where error ranges of the values were not given.

Table 2 Major elemental components in SRMs

$(\%: \mathrm{w} / \mathrm{w})$

\begin{tabular}{cccccccc}
\hline & C & Si & Mn & P & S & Nb & Mo \\
\hline SRM 361 & 0.383 & 0.222 & 0.66 & 0.014 & 0.0143 & 0.022 & 0.19 \\
SRM 363 & 0.62 & 0.74 & 1.50 & 0.029 & 0.0068 & 0.049 & 0.028 \\
SRM 364 & 0.87 & 0.065 & 0.255 & 0.01 & 0.0250 & 0.157 & 0.49 \\
\hline
\end{tabular}

*The values were certified reference values provided by the NIST. 
Table 3 Operating conditions of Agilent 8800 ICP-MS

\begin{tabular}{|c|c|}
\hline & Operating conditions \\
\hline RF power (W) & 1550 \\
\hline Carrier gas $\left(\mathrm{L} \mathrm{min}^{-1}\right)$ & 1.08 \\
\hline Skimar corn & Ni corn for $\mathrm{X}$ lens \\
\hline Sampling corn & Ni corn for $\mathrm{X}$ lens \\
\hline Selected mass-charge ratio for & Te $(125,126,128,130), Y(89)$ \\
\hline & $1^{\text {st }}$ mass filter: \\
\hline Selected mass-charge ratio for & $\mathrm{Te}(120.122,123,124,125,126,128,130)$ \\
\hline $\mathrm{O}_{2}$ mass shift mode & $2^{\text {nd }}$ mass filter: \\
\hline & $\mathrm{TeO}(136,138,139,140,141,142,144,146)$ \\
\hline Dwell time (ms) & 500 \\
\hline Mass scan times (scan) & 10 \\
\hline Total integration time $(\mathrm{s})$ & 5 \\
\hline
\end{tabular}


Table 4 Mass spectral interferences and natural isotopic abundance of Te isotopes ${ }^{12,13,22)}$

\begin{tabular}{|c|c|c|}
\hline $\begin{array}{l}\text { Isotopes } \\
\text { interfered }\end{array}$ & $\begin{array}{c}\text { Abundance } \\
\text { Te (\%) }\end{array}$ & Major interferences \\
\hline${ }^{125} \mathrm{Te}$ & 7.07 & ${ }^{93} \mathrm{Nb}^{16} \mathrm{O}_{2}^{+}$ \\
\hline${ }^{126} \mathrm{Te}$ & 18.84 & ${ }^{94} \mathrm{Mo}^{16} \mathrm{O}_{2}{ }^{+},{ }^{110} \mathrm{Pd}^{16} \mathrm{O}^{+},{ }^{126} \mathrm{Xe}^{+}$ \\
\hline${ }^{128} \mathrm{Te}$ & 31.74 & ${ }^{96} \mathrm{Mo}^{16} \mathrm{O}_{2}{ }^{+},{ }^{96} \mathrm{Ru}^{16} \mathrm{O}^{+},{ }^{93} \mathrm{Nb}^{35} \mathrm{Cl}^{+},{ }^{128} \mathrm{Xe}^{+}$ \\
\hline${ }^{130} \mathrm{Te}$ & 34.08 & ${ }^{98} \mathrm{Mo}^{16} \mathrm{O}_{2}{ }^{+},{ }^{98} \mathrm{Ru}^{16} \mathrm{O}_{2}{ }^{+},{ }^{130} \mathrm{Xe}^{+},{ }^{130} \mathrm{Ba}^{+}$ \\
\hline
\end{tabular}


Table 5 (a) Recoveries of $0.1 \mu \mathrm{g} \mathrm{L} \mathrm{L}^{-1}$ of Te in Fe solutions.

(unit: \%)

\begin{tabular}{|c|c|c|c|c|}
\hline \multirow{2}{*}{ Isotope measured } & \multirow{2}{*}{$\begin{array}{l}\text { Sample numbers and } \\
\text { the average values }\end{array}$} & \multicolumn{3}{|c|}{ Conditions of mass filter and CRC } \\
\hline & & No-gas mode & He collision mode & $\mathrm{O}_{2}$ mass shift mode \\
\hline \multirow{5}{*}{${ }^{125} \mathrm{Te}$} & No. 1 & 103 & 90.4 & 92.1 \\
\hline & No. 2 & 107 & 65.5 & 118 \\
\hline & No. 3 & 102 & 103 & 126 \\
\hline & Average $\pm \sigma$ & $104 \pm 2$ & $86.2 \pm 19$ & $112 \pm 18$ \\
\hline & $(\mathrm{RSD} \%)$ & $(2.1)$ & $(22)$ & (16) \\
\hline \multirow{5}{*}{${ }^{126} \mathrm{Te}$} & No. 1 & 105 & 97.8 & 82.4 \\
\hline & No. 2 & 115 & 94.5 & 114 \\
\hline & No. 3 & 117 & 111 & 110 \\
\hline & Average $\pm \sigma$ & $112 \pm 6$ & $101 \pm 9$ & $102 \pm 17$ \\
\hline & $(\operatorname{RSD} \%)$ & $(5.5)$ & $(8.5)$ & (17) \\
\hline \multirow{5}{*}{${ }^{128} \mathrm{Te}$} & No. 1 & 98.0 & 106 & 121 \\
\hline & No. 2 & 110 & 104 & 101 \\
\hline & No. 3 & 108 & 116 & 123 \\
\hline & Average $\pm \sigma$ & $105 \pm 6$ & $109 \pm 6$ & $115 \pm 12$ \\
\hline & $(\operatorname{RSD} \%)$ & $(6.2)$ & $(5.9)$ & (10) \\
\hline \multirow{5}{*}{${ }^{130} \mathrm{Te}$} & No. 1 & 98.9 & 92.7 & 92.5 \\
\hline & No. 2 & 110 & 116 & 121 \\
\hline & No. 3 & 110 & 103 & 96.9 \\
\hline & Average $\pm \sigma$ & $106 \pm 6$ & $104 \pm 11$ & $103 \pm 15$ \\
\hline & $(\operatorname{RSD} \%)$ & $(5.9)$ & $(11)$ & $(15)$ \\
\hline
\end{tabular}

*Recoveries were calculated as [determined weight of $\mathrm{Te}$ ] / [added weight of Te] $\times 100$. ** The samples were prepared from separated three electrolytic iron. The average values, the standard deviations $(\sigma)$, and the relative standard deviations (RSDs \%) were calculated from the determined values of the three samples. 
Table 5 (b) Recoveries of $0.1 \mu \mathrm{g} \mathrm{L^{-1 }}$ of Te in Fe and Mo solutions

(unit: \%)

\begin{tabular}{|c|c|c|c|c|}
\hline \multirow{2}{*}{ Isotope measured } & \multirow{2}{*}{$\begin{array}{l}\text { Sample numbers and } \\
\text { the average values }\end{array}$} & \multicolumn{3}{|c|}{ Conditions of mass filter and CRC } \\
\hline & & No-gas mode & He collision mode & $\mathrm{O}_{2}$ mass shift mode \\
\hline \multirow{4}{*}{${ }^{125} \mathrm{Te}$} & No. 1 & 116 & 91 & 141 \\
\hline & No. 2 & 113 & 102 & 95 \\
\hline & No. 3 & 115 & 79 & 60 \\
\hline & $\begin{array}{l}\text { Average } \pm \sigma \\
(\operatorname{RSD} \%)\end{array}$ & $\begin{array}{c}115 \pm 1 \\
(1.3)\end{array}$ & $\begin{array}{c}91 \pm 11 \\
\text { (13) }\end{array}$ & $\begin{array}{c}99 \pm 41 \\
(41)\end{array}$ \\
\hline \multirow{4}{*}{${ }^{126} \mathrm{Te}$} & No. 1 & 137 & 99.0 & 87.0 \\
\hline & No. 2 & 150 & 115 & 78.3 \\
\hline & No. 3 & 161 & 116 & 94.0 \\
\hline & $\begin{array}{c}\text { Average } \pm \sigma \\
(\text { RSD \%) }\end{array}$ & $\begin{array}{c}149 \pm 12 \\
(8.3)\end{array}$ & $\begin{array}{c}110 \pm 10 \\
(8.8)\end{array}$ & $\begin{array}{c}86.4 \pm 7.8 \\
(9.1)\end{array}$ \\
\hline \multirow{4}{*}{${ }^{128} \mathrm{Te}$} & No. 1 & 131 & 97.0 & 98.3 \\
\hline & No. 2 & 151 & 105 & 93.4 \\
\hline & No. 3 & 163 & 108 & 99.4 \\
\hline & $\begin{array}{l}\text { Average } \pm \sigma \\
(\operatorname{RSD} \%)\end{array}$ & $\begin{array}{c}149 \pm 16 \\
(11) \\
\end{array}$ & $\begin{array}{c}103 \pm 6 \\
(5.3) \\
\end{array}$ & $\begin{array}{c}97.0 \pm 3.2 \\
(3.3) \\
\end{array}$ \\
\hline \multirow{4}{*}{${ }^{130} \mathrm{Te}$} & No. 1 & 141 & 103 & 100 \\
\hline & No. 2 & 163 & 101 & 89.1 \\
\hline & No. 3 & 177 & 123 & 108 \\
\hline & $\begin{array}{l}\text { Average } \pm \sigma \\
(\operatorname{RSD} \%)\end{array}$ & $\begin{array}{c}160 \pm 18 \\
\text { (11) }\end{array}$ & $\begin{array}{c}109 \pm 12 \\
(11)\end{array}$ & $\begin{array}{l}99.2 \pm 9.6 \\
(9.7)\end{array}$ \\
\hline
\end{tabular}


Table 5 (c) Recoveries of $0.1 \mu \mathrm{g} \mathrm{L^{-1 }}$ of Te in Fe and $\mathrm{Nb}$ solution

(unit: \%)

\begin{tabular}{|c|c|c|c|c|}
\hline \multirow[b]{2}{*}{ Isotope measured } & \multirow{2}{*}{$\begin{array}{l}\text { Sample numbers and } \\
\text { the average values }\end{array}$} & \multicolumn{3}{|c|}{ Conditions of mass filter and CRC } \\
\hline & & No-gas mode & He collision mode & $\mathrm{O}_{2}$ mass shift mode \\
\hline \multirow{4}{*}{${ }^{125} \mathrm{Te}$} & No. 1 & 233 & 272 & 136 \\
\hline & No. 2 & 245 & 193 & 117 \\
\hline & No. 3 & 242 & 217 & 97.3 \\
\hline & $\begin{array}{c}\text { Average } \pm \sigma \\
(\operatorname{RSD} \%)\end{array}$ & $\begin{array}{c}240 \pm 6 \\
(2.7)\end{array}$ & $\begin{array}{c}227 \pm 40 \\
(18)\end{array}$ & $\begin{array}{c}117 \pm 19 \\
(17)\end{array}$ \\
\hline \multirow{4}{*}{${ }^{126} \mathrm{Te}$} & No. 1 & 120 & 134 & 101 \\
\hline & No. 2 & 113 & 106 & 81.3 \\
\hline & No. 3 & 110 & 123 & 99.3 \\
\hline & $\begin{array}{c}\text { Average } \pm \sigma \\
(\operatorname{RSD} \%)\end{array}$ & $\begin{array}{c}114 \pm 6 \\
(4.8)\end{array}$ & $\begin{array}{c}121 \pm 14 \\
(12)\end{array}$ & $\begin{array}{c}93.9 \pm 11 \\
(12)\end{array}$ \\
\hline \multirow{4}{*}{${ }^{128} \mathrm{Te}$} & No. 1 & 117 & 120 & 115 \\
\hline & No. 2 & 111 & 114 & 102 \\
\hline & No. 3 & 106 & 107 & 100 \\
\hline & $\begin{array}{c}\text { Average } \pm \sigma \\
(\text { RSD } \%)\end{array}$ & $\begin{array}{c}111 \pm 6 \\
(5.0) \\
\end{array}$ & $\begin{array}{c}113 \pm 7 \\
(5.8) \\
\end{array}$ & $\begin{array}{c}106 \pm 8 \\
(7.9) \\
\end{array}$ \\
\hline \multirow{4}{*}{${ }^{130} \mathrm{Te}$} & No. 1 & 116 & 113 & 91.1 \\
\hline & No. 2 & 112 & 103 & 118 \\
\hline & No. 3 & 104 & 101 & 102 \\
\hline & $\begin{array}{c}\text { Average } \pm \sigma \\
(\operatorname{RSD} \%)\end{array}$ & $\begin{array}{c}110 \pm 6 \\
(5.6)\end{array}$ & $\begin{array}{c}106 \pm 6 \\
(6.0)\end{array}$ & $\begin{array}{c}104 \pm 14 \\
\text { (13) }\end{array}$ \\
\hline
\end{tabular}


Table 6 Examination of mass discrimination effect on Te isotopes ${ }^{22}$

\begin{tabular}{ccccc}
\hline & Sample numbers & ${ }^{126} \mathrm{Te} /{ }^{125} \mathrm{Te}$ & ${ }^{128} \mathrm{Te} /{ }^{125} \mathrm{Te}$ & ${ }^{130} \mathrm{Te} /{ }^{125} \mathrm{Te}$ \\
\hline \multirow{4}{*}{ Measured } & No. 1 & 2.66 & 4.59 & 5.00 \\
& No. 2 & 2.66 & 4.38 & 4.84 \\
& No. 3 & 2.65 & 4.41 & 5.05 \\
\cline { 2 - 5 } & Average $\pm \sigma$ & $2.66 \pm 0.01$ & $4.46 \pm 0.12$ & $4.96 \pm 0.11$ \\
(RSD \%) & $(0.30)$ & $(2.6)$ & $(2.3)$ \\
\hline \multicolumn{2}{c}{ Natural isotopic abundance } & 2.66 & 4.49 & 4.82 \\
\hline
\end{tabular}

* The error range of measured isotopic abundance ratio is expressed as standard deviation $(\sigma)$. 
Table 7 Recovery test by ID-ICP-MS and ID-ICP-MS/MS after liquid-liquid extraction (unit: \%)

\begin{tabular}{cccc}
\hline \multirow{2}{*}{ Sample numbers } & \multicolumn{3}{c}{ Conditions of mass filter and CRC } \\
\cline { 2 - 4 } & No-gas mode & He collision mode & $\mathrm{O}_{2}$ mass shift mode \\
\hline No. 1 & 102 & 117 & 98.9 \\
No. 2 & 101 & 116 & 99.5 \\
No. 3 & 102 & 119 & 99.9 \\
\hline Average $\pm \sigma$ & $101 \pm 1$ & $117 \pm 1$ & $99.4 \pm 0.5$ \\
(RSD \%) & $(0.55)$ & $(1.1)$ & $(0.52)$ \\
\hline
\end{tabular}

*Recoveries were calculated as [determined weight of $\mathrm{Te}$ ] / [added weight of $\mathrm{Te}] \times 100$. ** The error ranges are expressed by standard deviations $(\sigma)$, and the values in the parentheses are the RSD values (\%) obtained by three individual determinations of the recovery test.

Table 8 Determination of Te in SRMs by ID-ICP-MS/MS

(unit: $\mu \mathrm{g} \mathrm{g}^{-1}$ )

\begin{tabular}{cccc}
\hline & SRM 361 & SRM 363 & SRM 364 \\
\hline No. 1 & 5.31 & 10.0 & 1.81 \\
No. 2 & 5.25 & 9.95 & 1.77 \\
No. 3 & 5.23 & 10.1 & 1.81 \\
\hline Average $\pm \sigma$ & $5.26 \pm 0.04$ & $10.0 \pm 0.05$ & $1.80 \pm 0.02$ \\
$($ RSD \%) & $(0.78)$ & $(0.51)$ & $(1.3)$ \\
\hline Reported value & 6 & 9 & 2 \\
\hline
\end{tabular}

*The error ranges are expressed by standard deviations $(\sigma)$, and the values in the parentheses are the RSD values (\%) obtained by three individual determinations of the recovery test. 


\section{Figure Captions}

Fig. 1 Liquid-liquid extraction procedure by 4-methyl-2-pentanone.

Fig. 2 Examination of mass spectral interference by Xe ions 


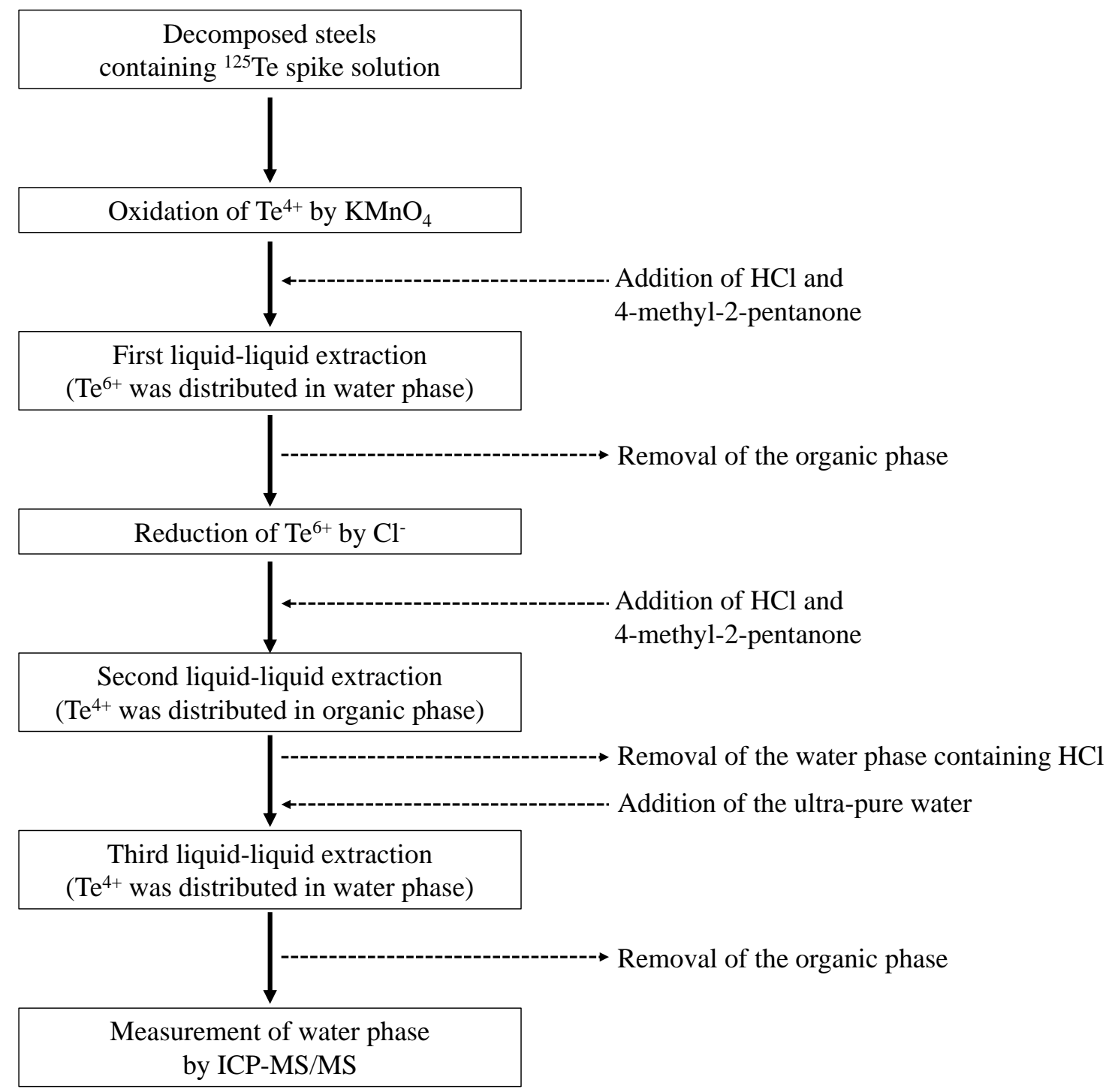

Fig. 1 

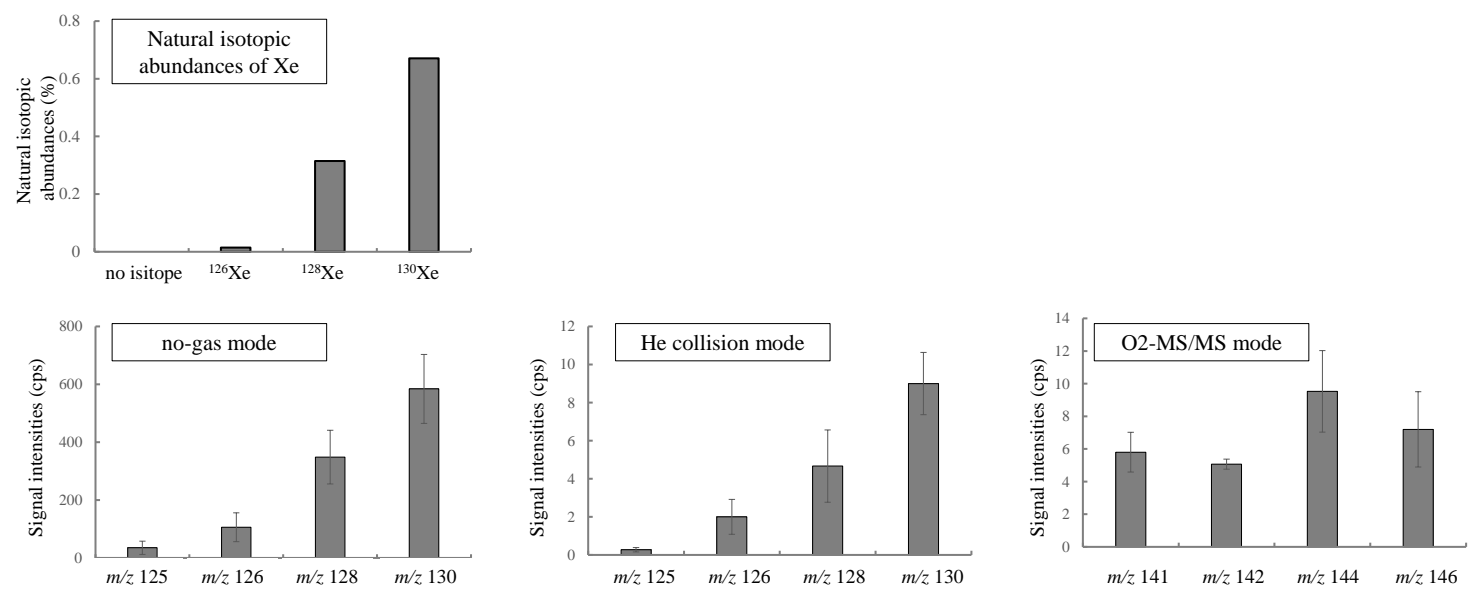

Fig. 2 


\section{Graphical Index}

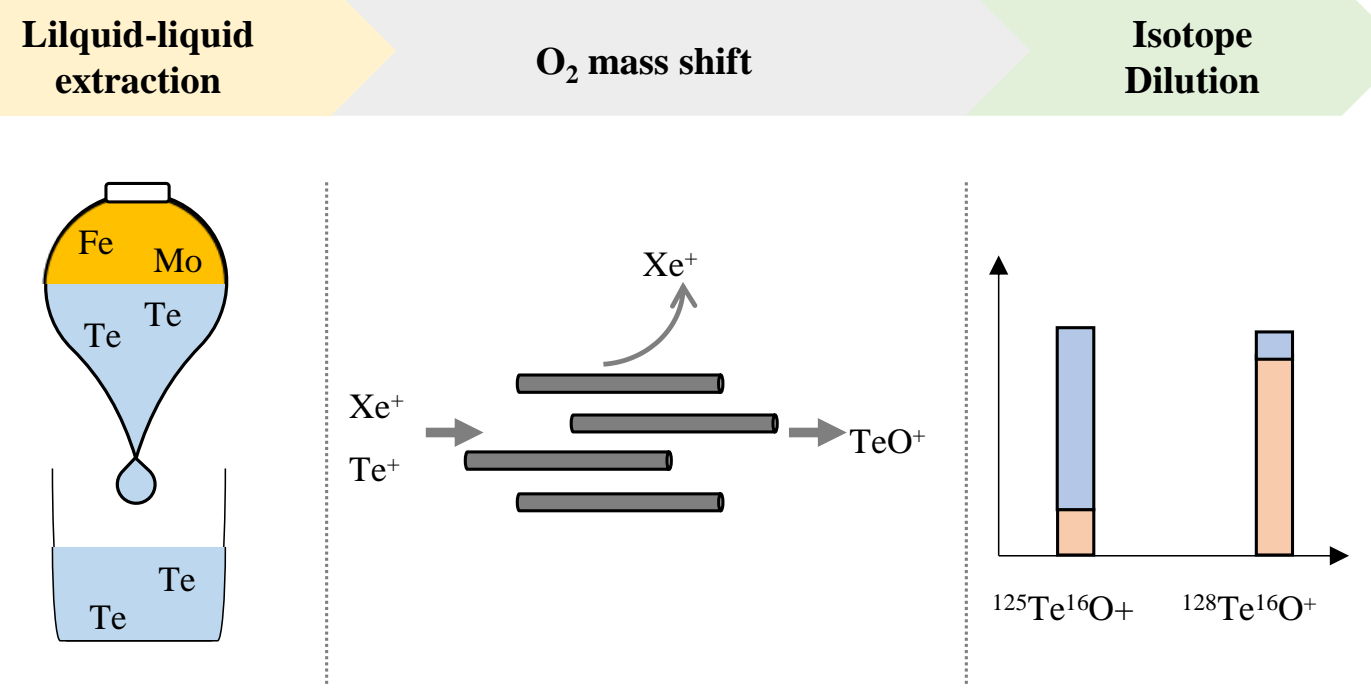

Determination of tellurium in steel samples by ID-ICP-MS/MS with liquid-liquid extraction 